\title{
Phenomenalism in Epistemology and Physicalism in Aesthetics
}

\author{
JACQUES MORIZOT \\ Université de Provence
}

\begin{abstract}
The starting point of this paper is the intriguing observation that Goodman has defended a phenomenalist point of view in his epistemological works and a physicalist one in aesthetics. In fact, it would certainly be more accurate to say that his focus was anti physicalist in epistemology and anti phenomenalist in aesthetics. In any case a majority of interpreters would spontaneously have waited for a diametrically opposite choice, more consistent indeed with the positions taken by the representatives in these fields. Yet Goodman's strategy is not arbitrary, it has deep roots in the general context of the philosophy in the twentieth century and in return contributes to clarify some of its features and motivation.
\end{abstract}

Keywords: Phenomenalism; physicalism; epistemology; aesthetics.

The starting point of this paper is the intriguing observation that Goodman has defended a phenomenalist point of view in his epistemological works and a physicalist one in aesthetics. In fact, it would certainly be more accurate to say that his focus was anti physicalist in epistemology and anti phenomenalist in aesthetics. In any case a majority of interpreters would spontaneously have waited for a diametrically opposite choice, more consistent indeed with the positions taken by the representatives in these fields. Yet Goodman's strategy is not arbitrary, it has deep roots in the general context of the philosophy in the twentieth century and in return contributes to clarify some of its features and motivation.

First it is worth mentioning that to state the problem in these terms may already seem questionable because the concept of 'phenomenalism' no longer occupies a prominent place in our contemporary philosophical horizon. As Putnam wrote in 1979, "Physicalism and 'realism' are at the high tide of fashion; phenomenalism has sunk out of sight in a slough of philosophical disesteem and neglect". ${ }^{1}$ Although not a totally alien or obsolete object, it is nonetheless a position that is hardly ever claimed for itself, much less as a starting point taken for granted or as a priority strategy. The current way to encounter phenomenalism is now through the history of doctrines, both in its ancient origins from Locke and Berkeley and throughout the great episode of revision in the theory of knowledge that leads from Mach's Analysis of Sensations in 1886 to Russell's early works and of course to Carnap's Aufbau (1928) which is the highest peak in this story. This book has a double importance in this context since it is associated with the first attempt to build an axiomatized

Principia 15(3): 439-452 (2011).

Published by NEL — Epistemology and Logic Research Group, Federal University of Santa Catarina (UFSC), Brazil. 
program on a phenomenal basis - it was not the aim of Mach, despite its epistemological ambitions - and that it constitutes a direct source of the work of Goodman as outlined in his first book, The Structure of Appearance (1951). As everybody knows, Goodman devotes the entire chapter 5 of his book to a critical examination of the first part of the difficult book by Carnap. He mentions in the foreword that Carnap and Quine have read with great care his thesis A Study of Qualities defended in 1940 "and made innumerable valuable suggestions" (SA viii) ${ }^{2}$ conversely, Carnap recalls in the 1961 preface to the second German edition of his book that "it is Nelson Goodman who went best into the problems broached in my book". It should also be borne in mind that the development of phenomenalism was in an historical perspective an alternative to the phenomenology of Husserl; the two doctrines share a same emphasis on the primacy of the perceived and the need for a method of constitution for knowledge but the constructionist orientation remains foreign to the notion of 'eidetic reduction', despite some superficial similarities in terminology.

My project is not to discuss Goodman's investigation of Carnap's system. I leave this topic to more competent analysts than I am. What will retain my attention is the internal articulation of his work, through the comparison of the proper evolution to the two authors, which are both similar in their external profile and totally dissimilar if not incompatible in what motivates them. Then I will add some remarks about the scope of Goodman's work by taking into account some contemporary readings.

The basic idea of phenomenalism is the fact that the world is not to be conceived as an absolute physical reality but as the shaping of a loose collection of sensory data from its own experience in the encounter of the sensible universe. As Hintikka writes, "what is given to us in immediate experience is not objects in their reality, but the impressions they leave on us". The primary motivation for phenomenalism lies undoubtedly in looking for an irrefutable epistemological basis because it is experienced in first person (Carnap speaks of 'autopsychic states') and it corresponds to an ultimate source of information about the real. Where to find indeed a more solid anchor than in the interface between the external world and our own sensory equipment? In this regard, the project aimed at by Neurath to match protocol sentences with real life language played a prominent role, whether or not this 'universal slang' has some originary status.

The reverse side of the coin is the threat of solipsism that imperils communicability and thus ultimately cast a doubt on the objectivity of knowledge. It may be surprising that Goodman gives little attention to this kind of discussion current among positivists (and especially Schlick), seeing it as a superficial effect of perspective. "Speaking from outside a phenomenalistic system, [he writes] one may describe its basis as solipsistic, may say that its basic units are comprised within a single stream of experience. But speaking from the point of view of the system itself, this is an anachronism. For the basic units of such a system are not taken as 
belonging to a subject and representing an object. They are taken as the elements in terms of which must be construed whatever objects, subjects, streams of experience, or other entities the system talks about at all." (SA 106) What explains his attitude is the fact is that he takes the issue of 'methodological solipsism' as settled by his master Clarence Irving Lewis, in a book almost contemporary of Carnap's, Mind and the World Order, published for the first time in 1929 and offering a close analysis of the origins and methods of knowledge. For Lewis, a philosophy can be judged basically by the type of method it implements. The one he advocates - that sends away vulgar empiricism as well as a dogmatic brand of rationalism - is a reflective method inspired by pragmatism that "recognizes experience in general as the datum of philosophy" (Lewis 1956, p. 33). without presupposing that the mind receives passively an imprint from the senses, or that this experience is ready-made. Lewis's position is in fact irreducible both to those that interpret the given as something immediate, pure sense-data correlative of our sensory organs, and those who deduce from the recurrence of content that they are to be identified with kinds of essences.

As noted by Sellars, the notion of sense-data results from the contamination of two logically independent ideas: the idea that there are inner episodes that do not require any learning from the subject and the idea that they provide a necessary and undeniable basis for empirical knowledge. But their status is nevertheless uncertain, oscillating between the physical and the mental. ${ }^{3}$ In principle, it is not the case of qualia, even there are interpretable in several ways. For Lewis, the decisive fact is that qualia are a sort of universals, namely "recognizable qualitative characters of the given, which may be repeated in different experiences" (p. 121) though nevertheless irreducible to the properties of objects themselves: the quale is the subjective side, directly intuited and unmistakable, while the property is objective, combined with a full spectrum of qualia, and open to fallible judgments. Therefore, Lewis adds, "the same property may be validly predicated on the basis of different presented qualia, and different properties may be signalized by the same presented quale" (p. 131).

In the terminology adopted by Goodman, we are here confronted to a system called realistic (or sometimes universalist) whose elements are repeatable, whereas those of a particularist system are irreducibly singular. The basis is made up of nonspecific qualitative parts playing the role of atoms: that is qualia of color, spot and moment, whose composition engenders concreta. Two points are important. On the one hand, this realism is not defined metaphysically, but epistemologically, by the ability to articulate the elements of experience, not in accordance with an ontological thesis about the reality of the world. ${ }^{4}$ All that matters here is a strategy for action, since, as Blackburn has shown, the behavior of a non realist with an objectivist orientation who permits public accessible protocols may be indistinguishable in practice from that of the realist, which obviously cannot be the case of the subjectivist anti-realist who deals with experienced occurrences. On the other hand, 
Goodman reminds us that admitting entities other than individuals does not conflict with the principle of nominalism since "nominalism excludes all except individuals but does not decide what individuals there are" (SA 149). ${ }^{5}$ Nominalism and phenomenalism are logically independent even if their joint adoption imposes serious constraints.

The choice of phenomenalism is indeed required because of its inherent advantages, and first its capacity to explain all of what can be known in terms of phenomena. "A phenomenal system is thus held to constitute a kind of epistemological reduction of the predicates it defines; the definitions indicate the testable, empirical, pragmatic significance of these predicates; and definability in the system provides a criterion of meaningfulness. To the phenomenalist, what cannot be explained in terms of phenomena is unknowable, and words purporting to refer to it are vacuous" (SA 102). Goodman's presentation is faithful to Carnap's concept of a 'constitutive definition' conceived as a general rule of translation of any proposition to another with only basic concepts (Aufbau §2). Moreover, "far from being an intellectual sin", any such deliberate strategy of over-simplification, at least when conscious and cautious, "is a prerequisite for investigation" (FFF, xiv).

A drastic reduction of ambitions is nevertheless to be noticed, clearly seen in the titles of the two books: Carnap is aiming at the world in its entirety, Goodman sticks to the point of view or system of appearances. Elgin is certainly right when she claims that Goodman does not espouse phenomenalism as a doctrine (Elgin 2009 , p. 135-6). but his choice to focus on appearances restricts the availability of methods. Vuillemin notes however that "the paradox of Goodman's project is that it deals with appearances, which seems to exclude the arbitrary, though treating them as if they were the elements in a theory" (Vuillemin 1971, p. 341). Unlike Carnap, Goodman does not believe that the adoption of a system is equivalent to a matter of convenience, so that we could translate a system as you like into another. Vuillemin comments that "whereas Carnap believed he was choosing a conventional mode of expression, Goodman chooses a philosophy or rather he chooses a philosophical way of experimenting" [id. 305]. The fundamental reason is that, for Carnap, language is not subject to any criteria of ontological commitment and independent of any object he is in charge of handling (principle of tolerance). To become aware of what looks strange in such a situation, it is probably convenient to ask what "would have answered a disciple of Ingres, and a disciple of Monet, grappling with each other, if some expert told them that they were only quarreling because of the style of their discourse, not the properties of their paintings" [307]. Fully consistent with himself, Goodman does not hesitate to write, much later however, that "a Piero della Francesca Christ and a Rembrandt one belong to worlds organized into different kinds" (WW 11), ${ }^{6}$ just as theories are.

Of course, Goodman is also indebted to the British empiricist tradition (cf. PP

Principia 15(3): 439-452 (2011). 
22, SA 102), that is to the "geographers of human reason" that Kant was celebrating in contrast to the current approach in terms of genesis and history. This influence is however counterbalanced by his critique of foundationalism. In the foreword to chapter I of Problems and Projects, Goodman remarks that the pluralistic statements in "The Way the World Is" seem to contradict his plea for a systematic analysis; in fact, as soon as one realizes that "the structure of the world of presystematic language is simply a world-structure under one world-description and not the structure of the world independent of any description" (PP 3), it becomes difficult to look for a structural correspondence between the world and our descriptions but it becomes more interesting to compare the merits of various descriptions, which encourages the adoption of a criterion such as extensional isomorphism. On close inspection, Goodman develops very early a critique of epistemological absolutism, conducted from the horizon of empirical perspective though emancipated vis-à-vis major philosophical dualisms. It calls for a fiabilist epistemology for which the problem of knowledge is less a matter of strong foundation than the possibility to explain how it is engaged and consolidated. The 1951 article, "Sense and Certainty" is particularly instructive because, while remaining faithful to the impulse given by Lewis, he gives sideways new insights on the subject. On the negative side, Goodman establishes that there is no sense to search for what is undoubtedly given, since the concepts of truth and certainty "apply to statements or judgments, not mere particles, materials or elements" (PP 62). This does not call into question the idea of the given, although it makes its articulation problematic. Is it then necessary to keep reference to judgments that are beyond any doubt to anchor knowledge? Contra Lewis (and of course Descartes), Goodman assumes that a probabilistic conception of knowledge (in the logical, not statistical, sense) "does not presuppose certainty but only initial credibility" (63). In fact certainty refers to the direct and irreducible character of the relationship between sensory experience and how to describe it, far more than the certainty of the content itself (64), in accordance with the anti-foundationalist criticisms of Sellars and Wittgenstein. For Goodman, this question means to establish a connection between language and what it describes, that is to question how the standard symbolic system is able of taking over to the experience data. His solution postulates that the meaning has its roots into signaling (66): there would be no language in effect, hence no discursive certainty, if certain non-verbal events were not likely to serve as signals for others. ${ }^{8}$ In other words, the acquisition of an initial language of any kind should be seen as the acquisition of a secondary symbolic system (71) in which bodily movements and other dimensions play a significant role. Gestures are not a language by themselves but they can be combined with other presentations to constitute an effective signal (63-64). This thread is rather discreet and never put forward; nonetheless it inspires much of the work of Goodman to come and finds an echo until his later philosophy, when it tries to replace the symbolic paradigm within 
the broader framework of a dynamic understanding. Here is a shift from a highly euphemistic concept of 'revision' (PP 5, 23) to a concept of 'reconception' much more demanding, even if he makes clear that it is a reconception (between others?) and not the unique or absolute conceivable reconception (PR 173-6). In the meantime, the impact of the theory of symbols has been felt at every level of analysis, leading to both a thematic continuity and a complete methodological rethinking.

It is against this background that Goodman's evolution from epistemological phenomenalism to a particular sort of physicalism makes sense. What Scheffler names an inscriptionnalist approach is undoubtedly in the spirit of nominalism but it is not necessarily a mandatory component. Rather it represents an original variant, which will take its full significance when dealing with fictions. It is also a powerful alternative against the pictorial theory of language that has inspired much speculation on the subject.

It would obviously be a serious misinterpretation to treat in parallel Goodman's and Carnap's evolution, especially when drawing the lesson that phenomenalism and nominalism are definitely some sort of rearguard action, a negligible area of resistance which desperate defense would make all its seduction. Such a reading is of little philosophical interest and of no biographical truth. There is certainly no doubt that the respective paths of Carnap and Goodman follow the same apparent trajectory but this leaves out the crucial point since Carnap's conversion is nothing than the adoption of a language more appropriate to his projects (his deeper involvement in the philosophy of physics), while that of Goodman rests on a paradox that keeps its whole force: if he has never renounced his sympathy for phenomenalism, the adoption of the theory of symbolism leads him to go into a new battle no less radical in the unmarked field of aesthetics.

Carnap does not change his subject of study, he becomes aware that there is a distance more and more difficult to cross between objects as they are perceived and scientific objects, whereas Goodman does not believe that "its insolubility [must be] taken as sufficient reason for completely abandoning the phenomenalistic approach" (SA 330). In his last book, Philosophical Foundations of Physics (1966), Carnap claims that it would theoretically be possible to express physical laws from any regular process, without even excluding the comings and goings of a man from his home because if they lack the regularity of clockwork, these events are of the same intersubjective order that the oscillations of a pendulum. The principle of tolerance has the effect to play down the adoption of any particular language, so Carnap is entitled to consider that the preference for a physical and behavioral repertoire does not involve any essential denial but ultimately technical advantages of simplicity and convenience. Conversely, for Carnap there is no legitimate site for aesthetics. Its statements are no less compromised than metaphysical ones and for the same reasons: the inability to generate a theoretical content adequate to its real purpose. In

Principia 15(3): 439-452 (2011). 
a famous 1931 paper ("The Overcoming of Metaphysics Through Logical Analysis of Language", Carnap 1931), he wrote that "metaphysicians are musicians without any musical talent. They have nonetheless a strong propensity to work in the medium of theory, linking concepts and thoughts. Instead of cultivating this inclination by sticking to science and satisfying otherwise his need for expression in art, the metaphysician mixes the two, and so generates a form that is of no benefit for knowledge and remains inadequate to the sense of life." Hence his unexpected but logical praise for Nietzsche who never sacrifices the empirical content and uses in his masterpiece Thus Spoke Zarathustra "not the mystifying form of theory, but openly, the form of art, poetry". Similar reproaches to aestheticians - that Carnap has never stated himself - have become commonplace in critical theory, pointing out the current confusion between affective and cognitive.

Apparently, Goodman is at least as critical as Carnap might be vis-à-vis aesthetics but takes up a totally different stance. He avows that he feels "an aversion to much that passed as philosophy of art before" (MOM 130) but when Frans Boenders asks him: "Do you think that your philosophy of art can contribute to understanding of art, when we see it or read it or hear it?" his answer is unequivocal: "Yes, I think that a conceptual apparatus that makes sense and is reasonably comprehensive can help." (125) And to see this through, he thinks that a non phenomenalist basis is preferable. Why?

A first point to take into account is the overwhelming weight of classical aesthetics that outlived the analytical revolution at the beginning of the $\mathrm{XX}^{\text {th }}$ century, as we can see in the case of Moore, one of its less suspect representatives, who remains attached to the natural prevalence of Beauty and the defense of Value. Perhaps the most lucid testimony is to be found in a paper by John Passmore who deplores both the lack of interest among British philosophers toward aesthetic issues and the correlative abuse of generalities; discourse escapes subjectivism only to sink in woolliness or finds refuge in technicalities (Passmore 1954, p. 45). Peter Lamarque notes however that American philosophers (J. Hospers, A. Isenberg, M. McDonald or M. Beardsley) give the example of a more committed attitude, not hesitating to publish in non specialized journals that are in principle less sensitive to the historian appeal (Lamarque 2000, p. 2-4). As an American philosopher, Goodman could have benefited from favorable conditions but in fact he did not developed for all that an aesthetically oriented research. We may even have a feeling that he did his utmost to divide his life into two distinct halves: on the one hand the kind of meticulous technical work of a philosopher-logician and on the other the management of a gallery, the life of an amateur and collector. In so doing, he expelled ipso facto from his conceptual horizon aesthetics as a discipline, sticking to the massive duality of art and logic. It is remarkable that he almost never mentions specialized works, either contemporary or past, not even by way of explicit repudiation of their content. It 
is only in the Preface to Languages of Art that he mentions cautiously "the lines of thought that joined [his] interest in the arts with [his] inquiries into the theory of knowledge" (LA V). However, Goodman will never be an analytical esthetician, eager to provide answers to questions arising in the field of aesthetics, let alone a metaesthetician who evaluates its principles and terms of relevance - even though he is one of the major analytic philosophers who have granted art the most important and indisputable significance.

It is not surprising that he replicates to Benjamin Boretz, one convinced defender of phenomenalism in art: "in general, I regard the choice between a phenomenalist and a physicalistic system as quite free, but I choose to treat works of art, or their instances, as physical rather than phenomenal in order to discourage what seems to me the mistaken and prevalent identification of the aesthetic with the immediate and uninterpreted" (PP 125). This gives good reason to be suspicious, or even motivates a strategy of resistance, but does it provide a positive reason to subscribe to a physicalist version and of what kind? The determining factor is to be sought in the role and impact of the theory of symbolization.

There is certainly a favorable context for developing a theory of symbols that goes through authors such as Peirce, Morris, Cassirer and Langer, but Goodman indeed owes very little to them, almost as little as to the nebulous symbolism feasted by the avant-garde. In particular, he has never had any sympathy for a unifying theory in which language would provide a universal key to interpret the diversity of works. Philosophy of language is needed as a conceptual basis, a directory of operating methods, not as a program to be implemented. The truth is that Goodman follows the reverse route: he does not go from language to personal and social meanings, like the semiologists, but from the world of appearances and literary diversity to an inscriptionnalist theory of language whose linguistic counterpart would probably be the behaviorist approach advocated by Bloomfield in linguistics. Language is not a model ready for transposition, it is first an object to be interpreted and foremost a tool matching with other sectors.

One of the first clues is the famous paper "On Likeness of Meaning" that would be almost incomprehensible without the inscriptionnalist option. Here he is broaching the case of synonymy in relation to non-existent or fictitious entities that raises a difficult problem for extensional semantics. "If we resolve to confine ourselves to terms and the things they refer to, renouncing concepts, intensions, senses, meanings, criteria in mind, and the like, how are we to do justice to the ostensible difference in meaning between two words, such as 'centaur' and 'unicorn' that have the same extension?" (PP 221) Goodman suggests to broaden the useful basis of extensional identity by taking into account the secondary extensions generated by the compounds of the predicate. This amounts to consider that, although 'centaur' and 'unicorn' are coextensive (since their extension is the same empty set), 'centaur- 
picture' and 'unicorn-picture' do not have the same meaning; nobody confuses them and they are not interchangeable in any ordinary context. These expressions are treated as monadic predicates that apply to different objects, as it is the case of any other term. And when there is no conceivable picture (for example with an odor or flavor), there are still descriptions or concepts of $\mathrm{X}$ that behave just like pictures, given that "actual word-inscriptions are as genuine physical objects as anything else" (PP 228). Goodman goes so far as to argue that "the string of inscriptions that we call a description is in effect merely a highly conventionalized picture" (232), an argument that will not resist to a comparative analysis of description and depiction. A classical objection raised by Davidson points to the generation of an infinite number of unstructured predicates that must all have the status of semantic primitives, with the result that it would be impossible to interpret such a language or to learn it (Davidson 2001, essays 1 and 7). Be that as it may, there is no doubt that the decision to treat words as syntactic replicas has played a decisive role in the form taken by the theory of symbolization.

It is worth noting that there is a strong affinity between extensional semantics and semiotics conceived as a theory of marks. It would indeed be perfectly conceivable to construct a theory of symbolization on other bases but the theory of notationnality developed in Languages of Art strongly affirms the epistemological continuity with Goodman's previous work. All the construction is made by reference to the syntax / semantics couple (with a logical priority of syntax) and on the basis of elementary units or marks, a term that subsumes utterances and verbal or graphic inscriptions (LA 169). If we exclude the case of sets that are structured only semantically and are unstable because the benefit of structuration is abolished by the lack of syntactic differentiation, this analysis eventuates into the well-known triad of non-notational sets (which do not meet any requisite for their marks and are dense), notational schemas (only syntactically structured characters) and notational systems (which are articulated both on a syntactical and semantical level). The remarkable point in this enterprise is not that it gives rise to a convenient classification of symbolic varieties used in the arts (the trilogy of sketches, scripts and scores), since Goodman should immediately concede that his definitions do represent idealizations of the actual categories, in the manner a perfect gas is to ambient air; it comes from evidence that it is a coherent extension of the systemic perspective taken in Structure of Appearance. An important part of Chapter IV of LA is devoted to technological analogies as well as problems of extrapolation in data processing. This chapter is in fact at the point of confluence between the logic of systems (SA), the justification of induction (FFF) and the creative invention of devices by art and technology.

It is therefore no exaggeration to say that Goodman's use of symbolisation is tantamount to a reconception of his antecedent program, with a significant shift 
of emphasis. In SA, he insisted on the deflationary properties of nominalism for "though nominalism leaves us wide freedom in our choice of predicates and individuals, it drastically curtails the means available to us for constructing a system" (SA 52). If it is unable to "select our raw materials or help us make good things out of bad materials", it is at least an efficient incentive to "help keep us from making bad things out of good materials" (PP 165). In LA, the nominalistic restriction is not abolished, however it goes back in the distance, so that one is given permission to use the set language in an agnostic manner. On the other hand, the decisive role is played by variation, the power to create multiple and imaginative solutions hitherto unexplored, as if the syntactic constraint was reversed into in a matrix for variation. Goodman is dealing with art, his discourse is informed by his own experience of passionate connoisseur, and he is writing at the same time the supplementary part that was missing from his constructionist program.

In brief there is a clear asymmetry between Carnap and Goodman: if the motivation of the first to depart from phenomenalism is the hope of achieving a "unified language of science", that of the second is rooted in the full recognition of the symbolic diversity. Given the failure of the positivist program, Carnap turned to the resources of modal logic and the semantics of possible worlds. But adoption of "the typical physicalism ... prodigal in the platonistic instruments" (WW 95) was not attractive to a frowning nominalist who has never made any difference between possible interpretations of these calculations. However, Goodman is increasingly aware that the interdependence between objects and how to know them which is at the heart of internal realism tends to push into the background the duality of phenomenalism versus physicalism: "that the instruments to be used in fashioning the facts must be specified makes pointless any identification of the physical with the real and the perceptual with the merely apparent. The perceptual is no more a rather distorted version of the physical facts than the physical is a highly artificial version of the perceptual facts" (WW 92-93) so that "the physical and perceptual world-versions mentioned are but two of the vast variety in the several sciences, in the arts, in perception and in daily discourse." (WW 93-94).

There is nonetheless some distance between talking about physicalist and phenomenalist systems and talking about physical and perceptual versions of the world, despite obvious factors of continuity. As a response, Goodman was going to claim a brand of irrealism whose contours certainly lack precision. Despite his insistence on the fact that anything does not create a version, let alone a correct version, and that the distinction between good and bad versions is never discarded, if the conditions for individuation remain vague, the benefit for an enlargement of perspective has chance of being compromised by the ups and downs of realization. So what emerges is a paradoxical result: where the analysis of Goodman is the most incisive, for instance in the set of definitions that provides the basis for LA, it is often if not always

Principia 15(3): 439-452 (2011). 
too strict for the ordinary purposes of a theory of the arts and it must set aside many of its daily concerns. But when it distances itself from semiotic categories, it becomes in danger of being trapped in ontological or epistemological pitfalls, in the kind of interference whose function of the theory of systems was precisely to contain.

At the end, it is still the same Goodman, with his enthusiasm and uncompromising attitudes, and yet almost everything has changed. From an epistemological point of view, the initial force of phenomenalism lay in the belief that all knowledge was expressible without losing contact with direct experience, whatever complex and delicate to handle is the theoretical apparatus. That of physicalism was inseparable from the belief that content articulated through naturalized sciences was the most effective. The theory of symbols is intermediate between the two and works on both sides, because it cannot renounce the care of phenomenal diversity and the ambition to develop a common grammar of representations. In this light, the task of the philosophy of art is to understand how works work, in both local and original interpretations. It retains the desire to be attentive to the frame without which no meaningful work can be evaluated or even correctly identified. Indeed, it developed an agnostic attitude towards universal coordinates or the intuitions of the artist or the reactions of an audience.

Given this background, where are we to look for Goodman's heritage? Of course what I have considered is only a thread in his oeuvre, in connection with the mentioned themes, and not the entire influence he is responsible for. It is the reason why I let aside the notion of exemplification and I agree with Catherine Elgin that it is one of the most fertile tools used by Goodman, even if we may wonder whether the sample is the best way to enter into the study of works of art. Exemplification has become more and more important in the course of modern art, for instance collage and especially pasted papers or performances or electronic music. All these productions mark a significant shift from expression to exemplification in its material and conceptual aspects. The difficulty is nonetheless to tell exemplification from free associations, along intricate chains of reference. One can otherwise suspect that the full recognition of its merits is hindered by the decline of semiotics.

Today seems bad days for of the intellectual trends adopted by Goodman. Almost nobody is still claiming to be a nominalist and one can even see a tide of metaphysical revenge. Modal realism has infiltrated everywhere. Subjectivism is flourishing and so on. Above all, the process of naturalization had spread out on every field, from epistemology to aesthetics. It would certainly be an error to conclude that this new paradigm is at odds with Goodman's orientation, even if his obstinate refusal to admit of mental representations makes the things more difficult. But some of the key concepts are also transferred to a new context. For example, the analog / digital distinction migrates from semiotics to the philosophy of mind and gets a new meaning or usage. For Goodman, it designated two alternative categories not to be possessed 
together by the same item; for Dretske otherwise, it refers to complementary descriptions - wide and narrow respectively - of the same content, the analog one dealing with perceptual apprehension and the digital with a propositional setting.

But the most important link is about the emphasis on systematic conditions. John Kulvicki is a prominent champion of a structural approach of pictures, though in a diverging sense from Goodman. Significantly, he writes in the first paragraph of his 2006 book that his starting point was a challenge to answer the question: "how could one manage to be so right and so wrong at the same time?" (Kulvicki 2006, p. vii). He pays tribute to Goodman to have focused his analysis on syntactic rather than visual features but he disagrees with his solution in terms of 'character constitutive aspects' because he shows they are not sufficient to characterize representational systems. Kulvicki's version of physicalism deals with the notion of 'bare-bones content', that is the iconic skeleton of a picture or what all interpretations of it must have in common, and it is totally free of any convention or familiarity. This can be patently seen in the case of linear perspective. Goodman was insisting on the idea that it does not obey the laws of geometrical optics whereas Kulvicki interprets it as an emblematic condition of iconic transparency. As a result, it is impossible to find sympathy for an indifferentist point of view where resemblance is something like a scarecrow.

So I can only agree with Dominic Lopes when he says that "Goodman gives no argument for anti-perceptualism beyond his refutation of the resemblance theory. He pays scant attention to real-world pictorial symbol systems" (Lopes 1996, p. 69). It was not for this matter the prevailing situation in epistemology where Goodman claims that "the multiple worlds I countenance are just the actual worlds made by and answering to true or right versions" (WW 94). Be that as it may, it seems necessary to come to 'incorporating perceptual elements within a symbolic framework' (12). Instead of sending away the theory of symbols and perception as two intractable opponents, it is preferable to be looking for some sort of agreement between them, the project of a perceptual theory of iconic symbols beyond the rivalry between Goodman and Schier (Schier 1986). A sensible point is mistrust toward "arbitrariness that is incompatible with the facts about pictorial competence" claims Lopes, because of its subordination to the linguistic model. For him, we cannot escape the fact that "any symbol system allows for generativity and transference when the system is rule-governed and competence in the system consists in grasping the rules governing the system" (72) rather than background knowledge only. To interpret any picture, one has to master patterns of visual salience, a fact not ignored by Goodman but relegated to a position of secondary importance (say the changing interests toward "the visual weighting of features of bulk or line or stance or light" brought up in WW 13). What Lopes offers is a sophisticated analysis that rests on a network of commitments and explicit non-commitments that have the effect of se- 
lecting some aspect and highlighting it. What seems to me an intriguing point is that one can rather easily find suggestive analogies between the two authors despite the differences in content and terminology.

In brief, my conviction is that, when this line of reasoning is followed, one is not unfaithful to Goodman's legacy, even if one is to renounce some of his most insistent topics. After all, every theory is just a milestone in a collective enterprise. Goodman has been a key forerunner and some of his insights are still promising and inescapable. Inscriptionalist physicalism imposed upon aesthetics a healthy regime, casting doubt on too gross categories and identifying misconceptions. But as most creative people he was unable to guess some major implications in relation to his theory. Rather paradoxically, he who was amongst all American philosophers the most reluctant to intentional programs may be said to have unwittingly hastened the cognitive revolution. It would be absurd to criticize him for that; however we have now the responsibility to read him also through the authors who took over from him.

\section{References}

Carnap, R. 1931. The Overcoming of Metaphysics Through Logical Analysis of Language. Erkenntnis 2: 219-41.

Davidson, D. 2001. Inquiries into Truth and Interpretation. 2nd ed. Oxford: Oxford University Press.

Elgin, C. Z. 2009. Construction and Cognition. Theoria 65: 135-46.

Kulvicki, J. 2006. On Images: Their Structure and Content. Oxford: Clarendon Press.

Lamarque, P. 2000. The British Journal of Aesthetics: Forty Years On. The British Journal of Aesthetics 40(1): 1-20.

Lewis, C. I. 1956. Mind and the World Order. New York: Dover.

Lopes, D. 1996. Understanding Pictures. Oxford: Clarendon Press.

Lowe, V. 1953. Professor Goodman's Concept of an Individual. The Philosophical Review 62(1): 117-26.

Passmore, J. 1954. The Dreariness of Aesthetics. In W. Elton (ed.) Aesthetics and Language. Oxford: Blackwell, 36-55.

Putnam, H. 1983. Reflections on Goodman's Ways of Worldmaking. In Realism and Reason (Philosophical Papers, 3). Cambridge: Cambridge University Press, p. 155-169.

Russell, B. The Relation of Sense-data to Physics. 1994. In Mysticism and Logic. London: Routledge.

Schier, F. 1986. Deeper into Pictures: An Essay on Pictorial Representation. Cambridge: Cambridge University Press.

Vuillemin, J. 1971. La logique et le monde sensible (Étude sur les théories contemporaines de l'abstraction). Paris: Flammarion.

Yolton, J. W. 1961. Seeming and Being. The Philosophical Quaterly 11(43): 114-22.

Wang, H. What Is an Individual? 1953. The Philosophical Review 62(3): 413-20.

Principia 15(3): 439-452 (2011). 
Resumo. O ponto de partida deste artigo é a observação intrigante de que Goodman defendeu um ponto de vista fenomenalista em suas obras epistemológicas, e fenomenalista em suas obras sobre estética. Na verdade, seria certamente mais preciso dizer que seu foco era antifisicalista em epistemologia e antifenomenalista na estética. De qualquer maneira, a maioria dos interpretadores teria, espontaneamente, esperado a escolha oposta, de fato mais consistente com as posições tomadas pelos representantes dessas áreas. Contudo, a estratégia de Goodman não é arbitrária, tendo raízes profundas no contexto geral da filosofia no século XX e, em compensação, contribui para esclareces algumas de suas características e motivação.

Palavras-chave: Fenomenalismo; fisicalismo; epistemologia; estética.

\section{Notes}

${ }^{1}$ Putnam 1983, p. 155. According to J. Yolton, the official death is July 1950 but he recognizes that ghosts have continued to haunt the grave (1961, p. 114).

${ }^{2}$ List of abbreviations used for Goodman's books: The Structure of Appearance (SA), Fact, Fiction and Forecast (FFF), Languages of Art (LA), Ways of Worldmaking (WW), Of Mind and Other Matters (MOM), Reconceptions in Philosophy and other Arts and Sciences (RP).

${ }^{3}$ B. Russell wrote that "sense-data are physical, and this being granted it is a matter of indifference in our present inquiry whether or not they are also mental" (Russell 1994, p. 145).

${ }^{4}$ The third thesis stated by Lewis in the preface of his book reads as follows: "that experience in general is such as to be capable of conceptual interpretation, requires no peculiar and metaphysical assumption about the conformity of experience to the mind or its categories; it could not conceivably be otherwise" (p. X).

${ }^{5}$ Also SA 52 et 175, PP 156-157. For a critical analysis of the notion of an individual, see the classical papers by V. Lowe (1953) and Hao Wang (1953).

6 "We have no neat set of frames of reference, no ready rules for transforming physics, biology, and psychology into one another, and no way at all of transforming any of these into Van Gogh's vision, or Van Gogh's into Canaletto's" (WW 3).

7 The paper was first a talk given at the symposium "The Experiential Element in Knowledge" with Lewis et Reichenbach (Bryn Mawr College, 29 December 1951), PP ch. II, 1.

${ }^{8}$ The first appearance of this idea is to be found in the Treatise on Human Nature (1650) by Hobbes (ch. V §1).

Principia 15(3): 439-452 (2011). 